\title{
Attitudes to specialist palliative care and advance care planning in people with COPD: a multi-national survey of palliative and respiratory medicine specialists
}

\author{
Natasha Smallwood ${ }^{1,2^{*}}$ (D), David Currow ${ }^{3}$, Sara Booth ${ }^{4}$, Anna Spathis ${ }^{5}$, Louis Irving ${ }^{1}$ and Jennifer Philip ${ }^{6,7}$
}

\begin{abstract}
Background: Chronic obstructive pulmonary disease (COPD) guidelines recommend early access to palliative care together with optimal, disease-directed therapy for people with advanced disease, however, this occurs infrequently. This study explored the approaches of respiratory and palliative medicine specialists to palliative care and advance care planning (ACP) in advanced COPD.

Methods: An online survey was emailed to all specialists and trainees in respiratory medicine in Australia and New Zealand (ANZ), and to all palliative medicine specialists and trainees in ANZ and the United Kingdom.

Results: Five hundred seventy-seven (33.1\%) responses were received, with 440 (25.2\%) complete questionnaires included from 177 respiratory and 263 palliative medicine doctors. Most respiratory doctors $(140,80.9 \%)$ were very or quite comfortable providing a palliative approach themselves to people with COPD. 113 (63.8\%) respiratory doctors recommended referring people with advanced COPD to specialist palliative care, mainly for access to: psychosocial and spiritual care (105, 59.3\%), carer support (104, 58.5\%), and end-of-life care (94, 53.1\%). 432 (98.2\%) participants recommended initiating ACP discussions. Palliative medicine doctors were more likely to recommend discussing: what palliative care is $(p<0.0001)$, what death and dying might be like $(p<0.0001)$ and prognosis $(p=$ 0.004). Themes highlighted in open responses included: inadequate, fragmented models of care, with limited collaboration or support from palliative care services.
\end{abstract}

Conclusions: While both specialties recognised the significant palliative care and ACP needs of people with advanced COPD, in reality few patients access these elements of care. Formal collaboration and bi-directional support between respiratory and palliative medicine, are required to address these unmet needs.

Keywords: COPD, Survey, Health professionals, Palliative care, Attitudes, Advance care planning

\section{Background}

Chronic obstructive pulmonary disease (COPD) is characterised by airflow limitation, persistent symptoms and respiratory failure [1]. By 2020, COPD is projected to be the third leading cause of death worldwide [2]. Yet despite many people expressing a desire to die at home,

* Correspondence: Natasha.smallwood@mh.org.au

'Department of Respiratory and Sleep Medicine, The Royal Melbourne Hospital, Melbourne, VIC 3050, Australia

${ }^{2}$ Department of Medicine (Royal Melbourne Hospital), University of Melbourne, Melbourne, VIC 3050, Australia

Full list of author information is available at the end of the article seven out of ten people with COPD die in hospital in Australia and the United Kingdom (UK) [3, 4].

Many patients with severe COPD experience reduced quality of life due to severe, chronic breathlessness, which persists at rest or on minimal exertion despite optimal treatment of the underlying causes [5-7]. Disease progression is also reflected in reduced function, limiting basic activities of daily living and requiring additional support from informal and paid caregivers, often for long periods of time [8]. In addition to other physical symptoms such as cough, pain, anorexia and fatigue, many patients have significant psychological comorbidity, with all these factors contributing to

(c) The Author(s). 2018 Open Access This article is distributed under the terms of the Creative Commons Attribution 4.0 International License (http://creativecommons.org/licenses/by/4.0/), which permits unrestricted use, distribution, and reproduction in any medium, provided you give appropriate credit to the original author(s) and the source, provide a link to the Creative Commons license, and indicate if changes were made. The Creative Commons Public Domain Dedication waiver (http://creativecommons.org/publicdomain/zero/1.0/) applies to the data made available in this article, unless otherwise stated. 
reduced quality of life and increasing social isolation for both patients and caregivers $[9,10]$.

Given the significant physical, psychosocial and communication needs of people with COPD [11], guidelines recommend that patients with advanced disease should receive early access to palliative care in conjunction with optimal, disease-directed therapy $[1,12]$. Therefore all health professionals have a role in providing palliative care to their patients [12]. Indeed when palliative care is provided by the usual treating clinician (such as the general practitioner or a medical specialist), it is termed generalist palliative care or a palliative approach [13]. By contrast, specialist palliative care is provided by health professionals who have specialist qualifications and/or significant experience in palliative care. Specialist palliative care teams not only support the usual treating clinician to offer a palliative approach, but have an important role in caring for people with challenging symptoms or complex needs [12]. Thus a palliative approach and specialist palliative care are not separate entities, but may be complementary aspects of care for patients with advanced COPD.

Despite guidelines recommending palliative care for people with advanced COPD, referral to specialist palliative care service occurs infrequently [14-16]. Only $1.7 \%$ of patients with end-stage COPD in the USA were referred to specialist palliative care when admitted with an exacerbation [16]. Similarly, in the UK and Australia only $16.7-17.9 \%$ of COPD patients accessed any specialist palliative care in their last year of life $[15,17,18]$. Yet people with severe COPD have documented needs which are similar to those of people at the end-of-life, irrespective of the underlying life-limiting illness [19]. Advance care planning $(\mathrm{ACP})$, which by definition should include discussion of each patient's palliative care wishes, also seldom occurs in routine practice [20-22].

Well-described barriers to accessing palliative care include difficulty prognosticating in COPD due to the variable disease trajectory [23, 24], clinicians lacking time to discuss palliative care or being fearful of taking away hope [25], and availability of specialist palliative care from services which are already overburdened $[26,27]$. Given these issues, a survey was undertaken to explore physicians' knowledge and practices managing people with advanced COPD. This manuscript reports current beliefs and practices of respiratory and palliative medicine doctors regarding the role of specialist palliative care and advance care planning in patients with severe COPD.

\section{Methods}

The full methodology including the research questionnaire utilised for this study have been published elsewhere [28], therefore the methods are summarised here.
A voluntary survey was designed for specialists and specialist trainees working in respiratory medicine in Australia and New Zealand (ANZ) and palliative medicine in ANZ and the United Kingdom (UK). The questionnaire included a case vignette describing an outpatient with severe COPD, receiving maximum disease modifying therapies and worsening, severe chronic breathlessness (modified Medical Research Council breathlessness score of 4). Survey participants were told the case patient did not have anxiety and was not in the terminal phase (last few days) of his illness. Respondents were asked to consider how they would manage the case patient or people with COPD similar to the case. All survey questions (including demographic information at the start of the survey) required an answer, before the respondent could proceed to the next question.

The link to the online survey (written in Survey Monkey) was distributed by the Thoracic Society of Australia and New Zealand, the Australian and New Zealand Society of Palliative Medicine, and the Association for Palliative Medicine of Great Britain and Ireland to their members. Each society member received two email invitations including the survey link, 2-4 weeks apart. The online survey was open to participants for six months from August 2015 to February 2016, with participants only able to submit one response from their IP address. Consent to participate was implied by completion of the survey questionnaire. Ethics approval was granted by the Melbourne Health Research Office (QA2014171). Separate ethics approvals from each specialist society were not required. Similarly health professional research studies that did not collect sensitive data, did not require ethics approval in the UK in 2015 [29].

\section{Statistical analysis}

Demographic data and responses are reported descriptively using frequencies and proportions. The Pearson Chi-Square test was used to identify associations between participants' responses and exposure variables measured as proportions (age, gender, country, specialty, position and location of practice); and Student's $t$ test was used for exposures measured as continuous numerical values (mean years worked in specialty and mean number of patients with severe COPD seen per month). Statistical analyses were performed using IBM SPSS Statistics Version 24.0, with a $p$-value of less than 0.05 indicating statistical significance. Free text responses to open ended questions were analysed using thematic analysis.

\section{Results}

Five hundred and seventy-seven (33.0\%) responses were received from 1047 doctors working in palliative medicine (323 in ANZ and 724 in the UK) and 702 working 
in respiratory medicine who were emailed the survey link. Responses were excluded from participants who: provided incomplete responses regarding patient management (94), were not respiratory or palliative medicine doctors (35), or were non-medical (8). Of the 440 (25.2\%) responses included, $263(25.1 \%)$ were palliative medicine doctors and 177 (25.2\%) participants were respiratory doctors (Table 1). Results from Australia and New Zealand were combined, given the smaller workforce and thus limited number of participants from New Zealand (21 palliative medicine specialists and 25 respiratory physicians).

The majority of respiratory doctors $(140,80.9 \%)$ reported being very or quite comfortable providing a palliative approach to people with COPD. Only eight (4.6\%) respiratory participants were quite or very uncomfortable offering this care, and the remainder were neutral. Respiratory doctors' demographic characteristics and experience (including age, gender, country, specialty, position and location of practice, mean years worked in specialty and mean number of patients with severe COPD seen per month) were not associated with level of comfort providing a palliative approach.

Almost two thirds of respiratory doctors (113, 63.8\%) recommended referring the person in the case vignette to specialist palliative care, with $90(50.8 \%)$ recommending referring for long-term specialist palliative care input and 23 (13.0\%) for an opinion only. Thirteen (7.3\%) participants were uncertain if they would refer and the remainder would not. Female respiratory doctors were twice as likely as their male colleagues to recommend referral to the specialist palliative care service $(\mathrm{OR}=2.0$,
$95 \% \mathrm{CI}=1.0-3.9, p=0.048)$. No other demographic characteristics or experience were associated with respiratory doctors recommending referral to specialist palliative care.

Respiratory doctors referred people with COPD for many reasons including for: psychosocial and spiritual care $(105,59.3 \%)$, carer support including future bereavement support $(104,58.5 \%)$, and end-of-life care $(94$, $53.1 \%$ ) (Table 2). Of the 64 (36.2\%) respiratory physicians who would not or were unsure if they would refer to specialist palliative care, 27 (15.3\%) reported being able to provide a palliative approach themselves, 19 $(10.7 \%)$ reported difficulty accessing palliative care in their location and 13 (7.3\%) thought the person described in the case vignette was unlikely to die within the next 12 months.

Nearly all doctors working in both respiratory (172, $97.2 \%)$ and palliative medicine $(260,98.9 \%)$ reported that they would initiate a discussion with the person in the case vignette (or similar people) regarding prognosis and advance care planning. Only 4 doctors (all respiratory) reported that they would not initiate this discussion with the person in the case vignette (or similar patients), with 2 reporting lack of time as a barrier. Holding the belief that advance care planning should be undertaken was not associated with any of the participants' demographic characteristics or experience for each specialty.

Both specialist groups recommended discussing multiple topics during ACP conversations including: mechanical ventilation and/or intensive care unit admission in the future, the utility of cardiopulmonary resuscitation, and the nature and role of palliative care (Table 3).

Table 1 Participant demographics

\begin{tabular}{|c|c|c|c|c|c|}
\hline & \multicolumn{3}{|c|}{ Palliative Medicine $(n=263)$} & \multirow{2}{*}{$\begin{array}{l}\text { Respiratory Medicine } \\
\text { ANZ }(n=177)\end{array}$} & \multirow[t]{2}{*}{ Specialties Compared } \\
\hline & ANZ $(n=129)$ & UK $(n=134)$ & All $(n=263)$ & & \\
\hline Female & $80(62.0 \%)$ & $112(83.6 \%)$ & $192(73.0 \%)$ & $61(34.4 \%)$ & $p<0.0001$ \\
\hline \multicolumn{6}{|l|}{ Age } \\
\hline $25-35$ & $25(19.3 \%)$ & $31(23.1 \%)$ & $56(21.3 \%)$ & $40(22.6 \%)$ & \multirow[t]{6}{*}{$p=0.953$} \\
\hline $36-45$ & $27(20.9 \%)$ & $50(37.3 \%)$ & $77(29.3 \%)$ & $57(32.2 \%)$ & \\
\hline $46-55$ & $31(24.0 \%)$ & $36(26.9 \%)$ & $67(25.5 \%)$ & $39(22.0 \%)$ & \\
\hline $56-65$ & $29(22.5 \%)$ & $15(11.2 \%)$ & $44(16.7 \%)$ & $27(15.3 \%)$ & \\
\hline$>65$ & $11(8.5 \%)$ & 0 & $11(4.2 \%)$ & $8(4.5 \%)$ & \\
\hline Missing & $6(4.7 \%)$ & $2(1.5)$ & $8(3.0 \%)$ & $6(3.4 \%)$ & \\
\hline \multicolumn{6}{|l|}{ Position } \\
\hline Consultant & $89(69.0 \%)$ & 107 (79.9\%) & $196(74.5 \%)$ & $145(81.9 \%)$ & \multirow[t]{2}{*}{$p=0.068$} \\
\hline Specialist trainee & $40(31.0 \%)$ & $27(20.1 \%)$ & $67(25.5 \%)$ & $32(18.1 \%)$ & \\
\hline Mean years in specialty ${ }^{a}$ & $12.5(9.1)$ & $12.3(7.3)$ & $12.4(8.2)$ & $15.0(10.8)$ & $p=0.006$ \\
\hline Mean no. of COPD patients seen/month ${ }^{a}$ & $3.1(3.1)$ & $2.5(3.4)$ & $2.8(3.3)$ & $14.1(12.0)$ & $p<0.0001$ \\
\hline
\end{tabular}

Data are represented as either frequencies or means (denoted by ${ }^{a}$ ), with either proportions or standard deviations in parentheses 
Table 2 Respiratory doctors' referrals to specialist palliative care

\begin{tabular}{lc}
\hline Reasons for referring COPD patients to palliative care & $N=113^{\mathrm{a}}$ \\
$\begin{array}{l}\text { For holistic care including psychosocial and } \\
\text { spitual care }\end{array}$ & $105(59.3 \%)$ \\
$\begin{array}{l}\text { For carer support including future bereavement } \\
\text { support }\end{array}$ & $104(58.8 \%)$ \\
For future end-of-life care & $94(53.1 \%)$ \\
To access community palliative care & $92(52.0 \%)$ \\
$\begin{array}{l}\text { To access respite care } \\
\text { breathlessness }\end{array}$ & $78(44.1 \%)$ \\
For completion of advance care planning & $75(42.4 \%)$ \\
Reasons for not referring COPD patients to & \\
palliative care & $63(36.2 \%)$ \\
I am capable of providing generalist palliative & $N=64^{b}$ \\
care myself & $27(15.3 \%)$ \\
$\begin{array}{l}\text { Palliative care services are difficult to access } \\
\text { in my location }\end{array}$ & $19(10.7 \%)$ \\
I do not think the patient might die in & \\
the next 12 months & $13(7.3 \%)$ \\
I do not want the patient to feel abandoned & $7(4.0 \%)$ \\
by me & \\
The patient does not require specialist palliative & $6(3.4 \%)$ \\
care yet & $4(2.3 \%)$ \\
I do not want to take away the patient's hope & $3(1.7 \%)$ \\
teams helpful for COPD patients & \\
\hline
\end{tabular}

Data are represented as frequencies with proportions of the total group $(n=$ 177) in parentheses

${ }^{a}$ Only participants who said they would refer to palliative care were directed to answer this question

${ }^{b}$ Only participants who said they would NOT/were unsure regarding referral to palliative care were directed to answer

Palliative medicine doctors were significantly more likely to recommend discussing: what palliative care is and whether indicated $(p<0.0001)$, what death and dying might be like from COPD $(\mathrm{p}<0.0001)$, the likely prognosis $(p=0.004)$ and changing treatment goals to aim for palliation $(p=0.028)$.

Many themes were identified in the extensive free text comments participants wrote, including that specialists believed current palliative care arrangements for people with advanced COPD are inadequate and fragmented:

"(This is a) difficult and big problem, and an area that clearly requires greater investment into formal palliative care services for this patient group, and greater formal systems of collaboration between respiratory physicians, palliative care teams, and community health providers." [Respiratory Medicine Specialist number 13, ANZ]
Fear of palliative care by both clinicians and patients was also noted as an issue:

"Of our palliative care patients I think they have the greatest number of unmet needs, but often they or their clinicians are fearful of what palliative care entails." [Palliative Medicine Specialist number 39, ANZ]

There was also concern that both people with COPD and their caregivers experience issues such as anxiety:

"COPD is hard to palliate. Patients find the exacerbations distressing and panic inducing. This also contributes to carer anxiety." [Palliative Medicine Specialist number 62, UK]

Additionally, limited available support from palliative care services currently was highlighted as an issue.

"Unfortunately our local palliative care service is under-resourced to support similar patients to this due to the frequent longevity of their needs. This is likely to be a growing problem in the future." [Respiratory Medicine Specialist number 71, ANZ]

Finally, both respiratory and palliative medicine physicians raised concerns regarding each other's knowledge and practices.

"Palliative care physicians manage this (COPD patients) very poorly." [Respiratory Medicine Specialist number 4, ANZ]

"It's end organ disease - we need to enable respiratory physicians to manage their patients in all phases of the illness, and use consultative services when necessary, rather than 'handing over' care to palliative care when goals of care are palliative." [Palliative Medicine Specialist number 57, UK]

\section{Discussion}

Recent international surveys of respiratory doctors have examined referral practices to specialist palliative care in the context of organisation of current service models, availability and local health policies $[21,30,31]$. In this large, multi-national study spanning three countries, in addition to examining recognised barriers to referring to specialist palliative care, we also uniquely identified that the majority of respiratory doctors are comfortable providing a palliative approach, but also recognise the role of specialist palliative care for people with advanced COPD. Additionally, both respiratory and palliative 
Table 3 Recommended ACP discussion topics

\begin{tabular}{|c|c|c|}
\hline & Resp Med & Pall Med \\
\hline \multicolumn{3}{|l|}{ ACP topics } \\
\hline The utility of CPR in the future & $159(89.8 \%)$ & $249(94.7 \%)$ \\
\hline Mechanical ventilation and/or ICU admission in the future & $164(92.7 \%)$ & $241(91.6 \%)$ \\
\hline What palliative care is and if this is indicated & $139(78.5 \%)$ & $246(93.5 \%)$ \\
\hline What death and dying might be like from COPD & $97(54.8 \%)$ & $200(76.0 \%)$ \\
\hline The likely prognosis in months and years & $100(56.5 \%)$ & $191(72.6 \%)$ \\
\hline Changing treatment goals to be palliative & $111(62.7 \%)$ & $191(72.6 \%)$ \\
\hline Appointing a medical power of attorney or substitute decision maker & $123(69.5 \%)$ & $185(70.3 \%)$ \\
\hline Other treatment limitations & $4(2.3 \%)$ & $20(7.6 \%)$ \\
\hline \multicolumn{3}{|l|}{ Other suggested topics } \\
\hline Desired place of future care (home/hospital/hospice) & 0 & $39(14.8 \%)$ \\
\hline Desired place of death & 0 & $37(14.1 \%)$ \\
\hline The patient's goals, values, wishes, hopes \& fears & $2(1.1 \%)$ & $27(10.3 \%)$ \\
\hline Ascertain the patient's understanding and knowledge first & $3(1.7 \%)$ & $4(1.5 \%)$ \\
\hline Patient led discussion & 0 & $22(8.4 \%)$ \\
\hline Future wishes regarding antibiotics & $3(1.7 \%)$ & $10(3.8 \%)$ \\
\hline Future wishes regarding NIV & $3(1.7 \%)$ & $9(3.4 \%)$ \\
\hline Advance treatment directives & 0 & $12(4.6 \%)$ \\
\hline Making a will or arranging affairs & $1(0.6 \%$ & $7(2.7 \%)$ \\
\hline
\end{tabular}

Data are represented as frequencies with proportions of the total group $(n=177)$ in parentheses

CPR Cardiopulmonary resuscitation, ICU Intensive Care Unit, NIV Non-invasive ventilation

medicine doctors acknowledge the importance of ACP discussions and identify similar key topics to discuss. However, current working models are considered inadequate with insufficient communication and collaboration between the many health professionals often involved in caring for people with advanced COPD.

\section{Attitudes to palliative care}

The vast majority of respiratory doctors from Australia and New Zealand, including doctors in specialist training, reported being very or quite comfortable providing a palliative approach to people with COPD. This finding is novel and may partly explain why people with COPD are infrequently referred to specialist palliative care services in Australia [15, 17]. Interestingly few participants in this study reported poor access to specialist palliative care services as an obstacle to referring COPD patients. By contrast respiratory physicians in the UK, Netherlands, and Sweden have cited lack of access to specialist palliative care services as an important barrier for people with COPD [32]. Instead, in this study participants highlighted that whilst specialist palliative care services were available, these services did not have the capacity or experience to manage advanced COPD patients, and importantly established relationships between respiratory and palliative medicine were absent.
Senior doctors' attitudes to specialist palliative care have been described as a barrier to referring people with cancer to these services [33]. However, the majority of respiratory doctors in our study recognised the benefits of referring people with advanced COPD to specialist palliative care. However, some respiratory doctors focussed on the prognosis and limited survival, as opposed to patients' needs when considering referral to specialist palliative care. Notably female doctors were considerably more likely to recommend referral to specialist palliative care. Likewise, when Australian junior doctors within their first five years of qualifying were surveyed (using this same questionnaire) regarding their knowledge and experiences managing people with advanced COPD, female trainees were approximately three times more likely to suggest referring to palliative care than male trainees [34]. This consistent finding requires further investigation to understand the reasons behind this difference in female doctors' reported practices.

The principle reasons for referring to specialist palliative care in this survey were for access to psychosocial and spiritual care, carer support including bereavement support, and end-of-life care. A survey of British respiratory physicians also identified that the main reasons for seeking specialist palliative care for people with chronic lung diseases were for end-of-life care (63\%) and psychological support (70\%) [21]. Likewise, Australian junior 
doctors reported referring people with COPD to specialist palliative care to access community palliative care input (54\%) and end-of-life care (45\%) [34]. However, in the current study, respiratory doctors less commonly recommended referral for symptom management (42\%), compared to $63 \%$ of British respiratory physicians and $62 \%$ of Australian junior doctors who referred for this reason [21, 34]. This would suggest that the ANZ respiratory doctors surveyed in this study not only feel comfortable providing a palliative approach, but also have greater confidence in managing difficult symptoms such as chronic breathlessness. However, there remains a significant need for specialist palliative care for people with COPD, particularly for psychosocial and existential support, addressing communication needs and for bereavement support of carers [11].

\section{Advance care planning}

The significant need for good communication and ACP in people with COPD and their carers is well-described $[35,36]$, and in this study was almost universally recognised. The responsibility for ACP rests with respiratory doctors as suggested by the majority of respondents in this study. Notably, while both specialties suggested similar topics should be covered within ACP and that it may involve several discussions, palliative medicine doctors were more likely to address challenging topics such as death and dying, prognosis, treatment limitations and place of future care as part of these discussions. Similarly, palliative medicine doctors recommended patient-led ACP discussions. Both specialties therefore report being engaged with ACP and their different approaches and skills appear to be complementary over the series of ACP conversations a patient may require. Therefore ideally respiratory doctors should initiate these discussions, and palliative medicine doctors can then develop and expand the conversation as the illness progresses and according to each person's needs and wishes.

\section{Models of care}

Confidence providing a palliative approach, managing difficult symptoms such as chronic breathlessness and awareness regarding the importance of ACP in people with advanced COPD does not necessarily translate into practice. A number of authors have documented the significant unmet palliative care needs reported by COPD patients [35] and the infrequent engagement in ACP discussions [21, 22, 25, 35, 37], suggesting a mismatch between our participants' responses and actual day-to-day clinical practice. Therefore it is not lack of awareness or confidence that is preventing clinicians from addressing the significant needs of people with advanced COPD. While lack of time may be a barrier, participants in this study raised concerns regarding the educational needs of doctors in each specialty and highlighted that current models of care are fragmented, with little collaboration between respiratory medicine, palliative medicine or primary care. Accessible, integrated, multi-disciplinary services, which embrace collaboration, trust and bi-directional education and support between both respiratory medicine and palliative care may overcome some of these issues [38]. Such integrated services include the Melbourne Advanced Lung Disease Service [39], and the London Breathlessness Support Service [40], both of which have demonstrated improved outcomes for people with COPD. However, larger, multi-site trials are required to fully assess these new models of care.

This study has some limitations. We had intended to survey British respiratory physicians, however, the British Thoracic Society declines to disseminate research surveys to its members. The response rate in this study, whilst similar to other online surveys of physicians [4143], was low, thus limiting the generalisability of our findings. However, the gender and age characteristics of participants in this study were representative of the workforce demographics in all three countries $[14,17$, 44-46]. Additionally, surveys require respondents to make black and white decisions to hypothetical scenarios, whereas in clinical practice these issues are not absolutely clear, instead requiring careful consideration.

\section{Conclusions}

Both respiratory and palliative medicine doctors recognised the significant palliative care and ACP needs of people with advanced COPD. Respiratory doctors reported being comfortable providing a palliative approach and acknowledged the role of both specialist palliative care and ACP, yet in reality people with advanced COPD rarely access these elements of care. Additionally, current models of care for people with COPD were considered inadequate and fragmented. Collaboration, trust, and bi-directional education between respiratory and palliative medicine, perhaps through integrated, multidisciplinary services, are urgently required to address the unmet needs of people with advanced COPD.

\footnotetext{
Abbreviations

ACP: Advance care planning; ANZ: Australia and New Zealand; COPD: Chronic obstructive pulmonary disease
}

\footnotetext{
Acknowledgements

The authors would like to thank: Prof Danny Liew for initial suggestions regarding the questionnaire design; A/Prof Brian Le, A/Prof Lutz Beckert and Dr. Amanda Landers for providing local workforce data. We also thank the Thoracic Society of Australia and New Zealand, the Australian and New Zealand Society of Palliative Medicine, and the Association for Palliative Medicine of Great Britain and Ireland for supporting and distributing the survey to their members. We gratefully acknowledge the organisers of the following meetings who allowed us to distribute paper copies of the survey to attendees: the 13th Australian Palliative Care Conference (2015), the 3rd Australian Palliative Care Research Colloquium (2015), the Victorian Palliative
} 
Medicine Advanced Trainees meeting (2015) and the Thoracic Society of Australia and New Zealand Victorian Branch Annual Scientific Meeting (2015).

\section{Funding}

Palliative Care Research Network provided research funding as a PhD scholarship for Dr. Natasha Smallwood. The funding body was not involved in any part of the study design, data collection, analysis or interpretation, or in writing the manuscript.

\section{Availability of data and materials}

The datasets used and/or analysed during the current study are available from the corresponding author on reasonable request.

\section{Authors' contributions}

NS conceived the idea for the study, designed all aspects of the study, conducted the research survey, and analysed the data. DC, SB, AS, LI, and JP all contributed to the study design and set up. NS wrote the first draft of the manuscript, with all authors commenting on and contributing to successive drafts of the manuscript. NS oversaw the entire research study and JP is the guarantor. All authors had full access to all of the study data and take responsibility for the integrity of the data, data analysis and presentation of the data in this manuscript. All authors have approved this manuscript for publication.

\section{Ethics approval and consent to participate}

Ethics approval was granted by the Melbourne Health Research Office (QA2014171). As this was health professional research study that did not collect sensitive data, it did not require review by a research ethics committee in the UK in 2015 [29]. Consent to participate was implied by completion of the survey questionnaire.

\section{Consent for publication}

\author{
Not applicable.
}

\section{Competing interests}

Dr. Sara Booth is a member of the editorial board (Associate Editor) for BMC Palliative Care. The other authors declare that they have no competing interests.

\section{Publisher's Note}

Springer Nature remains neutral with regard to jurisdictional claims in published maps and institutional affiliations.

\section{Author details}

${ }^{1}$ Department of Respiratory and Sleep Medicine, The Royal Melbourne Hospital, Melbourne, VIC 3050, Australia. ²Department of Medicine (Royal Melbourne Hospital), University of Melbourne, Melbourne, VIC 3050, Australia. ${ }^{3}$ IMPACCT - Improving Palliative, Aged and Chronic Care through Clinical Research and Translation, Faculty of Health, University of Technology Sydney, Ultimo, NSW, Australia. ${ }^{4}$ University of Cambridge, Cambridge, UK.

${ }^{5}$ Cambridge University Hospitals NHS Foundation Trust, Cambridge, UK ${ }^{6}$ Palliative Medicine, St Vincent's Hospital and Victorian Comprehensive Cancer Centre, University of Melbourne, Melbourne, Australia. ${ }^{7}$ St Vincent's Hospital, Victoria Parade, Melbourne, VIC 3065, Australia.

\section{Received: 31 July 2018 Accepted: 1 October 2018}

\section{Published online: 15 October 2018}

\section{References}

1. GOLD, Global initiative for chronic obstructive lung disease (GOLD). Global strategy for the diagnosis, management and prevention of COPD (2018 report). Available from: http://www.goldcopd.org. Accessed June 2018. 2018.

2. Collaborators, G.B.D.C.R.D. Global, regional, and national deaths, prevalence, disability-adjusted life years, and years lived with disability for chronic obstructive pulmonary disease and asthma, 1990-2015: a systematic analysis for the global burden of disease study 2015. Lancet Respir Med. 2017;5(9): $691-706$.

3. National End of Life Care Programme/National End of Life Care Intelligence Network. Deaths from respiratory diseases: implications for end of life care in England. June 2011. http://www.endoflifecare-intelligence.org.uk. Accessed April 2017.
4. Australian Institute of Health and Welfare (AlHW): Poulos LM, Cooper SJ, Ampon R, Redell HK and Marks GB 2014. Mortality from asthma and COPD in Australia. Cat. no. ACM 30. Canberra: AlHW.

5. Abernethy AP, Currow DC, Frith P, Fazekas BS, McHugh A, Bui C. Randomised, double blind, placebo controlled crossover trial of sustained release morphine for the management of refractory dyspnoea. BMJ. 2003: 327(7414):523-8.

6. Blinderman CD, Homel P, Billings JA, Tennstedt S, Portenoy RK. Symptom distress and quality of life in patients with advanced chronic obstructive pulmonary disease. J Pain Symptom Manag. 2009;38(1):115-23.

7. Johnson MJ, Yorke J, Hansen-Flaschen J, Lansing R, Ekstrom M, Similowski T, Currow DC. Towards an expert consensus to delineate a clinical syndrome of chronic breathlessness. Eur Respir J. 2017;49(5).

8. Johnson MJ, Bowden JA, Abernethy AP, Currow DC. To what causes do people attribute their chronic breathlessness? A population survey. J Palliat Med. 2012;15(7):744-50.

9. Hanania NA, Mullerova H, Locantore NW, Vestbo J, Watkins ML, Wouters EF, Rennard SI, Sharafkhaneh A. And C.L.t.I.P.S.E.s.i. evaluation of, Determinants of depression in the ECLIPSE chronic obstructive pulmonary disease cohort. Am J Respir Crit Care Med. 2011;183(5):604-11.

10. Kunik ME, Roundy K, Veazey C, Souchek J, Richardson P, Wray NP, Stanley MA. Surprisingly high prevalence of anxiety and depression in chronic breathing disorders. Chest. 2005;127(4):1205-11.

11. Disler RT, Green A, Luckett T, Newton PJ, Inglis S, Currow DC, Davidson PM. Experience of advanced chronic obstructive pulmonary disease: metasynthesis of qualitative research. J Pain Symptom Manag. 2014;48(6): 1182-99.

12. Lanken PN, Terry PB, Delisser HM, Fahy BF, Hansen-Flaschen J, Heffner JE, Levy M, Mularski RA, Osborne ML, Prendergast TJ, Rocker G, Sibbald WJ, Wilfond B, Yankaskas JR, Force ATSE-o-LCT. An official American Thoracic Society clinical policy statement: palliative care for patients with respiratory diseases and critical illnesses. Am J Respir Crit Care Med. 2008;177(8):912-27.

13. Palliative Care Australia. Service provision in Australia: a planning guide. 2003. 2nd edition. http://palliativecare.org.au/wp-content/uploads/2015/07/ Palliative-Care-Service-Provision-in-Australia-a-planning-guide.pdf. Accessed 18/03/18.

14. Australian Institue of Health and Welfare. 2017. Medical practitioners workforce 2015. http://www.aihw.gov.au/reports/workforce/medicalpractitioners-workforce-2015/contents/what-types-of-medical-practitionersare-there. Accessed 10/11/17

15. Rosenwax L, Spilsbury K, McNamara BA, Semmens JB. A retrospective population based cohort study of access to specialist palliative care in the last year of life: who is still missing out a decade on? BMC Palliat Care. 2016;15:46.

16. Rush B, Hertz P, Bond A, McDermid RC, Celi LA. Use of palliative Care in Patients with end-Stage COPD and receiving home oxygen: National Trends and barriers to Care in the United States. Chest. 2017;151(1):41-6.

17. Australian Institute of Health and Welfare (AlHW). 2017. Palliative care services in Australia. http://www.aihw.gov.au/reports/palliative-care-services/ palliative-care-services-in-australia/contents/palliative-care-workforce. Accessed 10/11/17. 2017.

18. Bloom Cl, Slaich B, Morales DR, Smeeth L, Stone P, Quint JK. Low uptake of palliative care for COPD patients within primary care in the UK. Eur Respir J. 2018;51(2).

19. Luddington L, Cox S, Higginson I, Livesley B. The need for palliative care for patients with non-cancer diseases: a review of the evidence. Int J Palliat Nurs. 2001;7(5):221-6.

20. Heffner JE, Fahy B, Hilling L, Barbieri C. Attitudes regarding advance directives among patients in pulmonary rehabilitation. Am J Respir Crit Care Med. 1996;154(6 Pt 1):1735-40.

21. Partridge MR, Khatri A, Sutton L, Welham S, Ahmedzai SH. Palliative care services for those with chronic lung disease. Chron Respir Dis. 2009;6(1):13-7.

22. Smallwood N, Taverner J, Bartlett C, Ross L, Irving L, Philip J. Palliation of patients with Chronic Obstructive Pulmonary Disease (COPD). Eur Respir J. 2016;48(Suppl. 60):3767.

23. Lunney JR, Lynn J, Foley DJ, Lipson S, Guralnik JM. Patterns of functional decline at the end of life. JAMA. 2003;289(18):2387-92.

24. Murray SA, Kendall M, Boyd K, Sheikh A. Illness trajectories and palliative care. BMJ. 2005;330(7498):1007-11.

25. Knauft E, Nielsen EL, Engelberg RA, Patrick DL, Curtis JR. Barriers and facilitators to end-of-life care communication for patients with COPD. Chest. 2005;127(6):2188-96 
26. Palliative Care Australia. 2010. Workforce for quality care at the end of life position statement. Available at: http://palliativecare.org.au/positionstatements. Accessed May 2017.

27. Quill TE, Abernethy AP. Generalist plus specialist palliative care--creating a more sustainable model. N Engl J Med. 2013;368(13):1173-5.

28. Smallwood N, Currow D, Booth S, Spathis A, Irving L, Philip J. Differing approaches to managing the chronic breathlessness syndrome in advanced COPD: a multi-National Survey of specialists. COPD. 2018:1-9. https://doi. org/10.1080/15412555.2018.1502264.

29. NHS Health Research Authority \& National Research Ethics Service. Does my project require review by a Research Ethics Committee? 2013. https://www. hra.nhs.uk/approvals-amendments/what-approvals-do-i-need/researchethics-committee-review/. Accessed 1/6/2015.

30. Duenk RG, Verhagen C, Dekhuijzen P, Vissers K, Engels Y, Heijdra Y. The view of pulmonologists on palliative care for patients with COPD: a survey study. Int J Chron Obstruct Pulmon Dis. 2017;12:299-311.

31. Strang S, Ekberg-Jansson A, Strang P, Larsson L. Palliative care in COPD web survey in Sweden highlights the current situation for a vulnerable group of patients. Ups J Med Sci. 2017;118(3):181-6.

32. Duenk RG, Verhagen C, Bronkhorst EM, Djamin RS, Bosman GJ, Lammers E, Dekhuijzen P, Vissers K, Engels Y, Heijdra Y. Development of the ProPalCOPD tool to identify patients with COPD for proactive palliative care. Int J Chron Obstruct Pulmon Dis. 2017;12:2121-8.

33. Fadul N, Elsayem A, Palmer JL, Del Fabbro E, Swint K, Li Z, Poulter V, Bruera E. Supportive versus palliative care: what's in a name?: a survey of medical oncologists and midlevel providers at a comprehensive cancer center. Cancer. 2009;115(9):2013-21.

34. Smallwood N, Gaffney N, Gorelik A, Irving L, Le B, Philip J. Doctors' attitudes to palliation and palliative Care in Patients with Advanced Chronic Obstructive Pulmonary Disease. J Pain Symptom Manag. 2017.

35. Maddocks M, Lovell N, Booth S, Man WD, Higginson IJ. Palliative care and management of troublesome symptoms for people with chronic obstructive pulmonary disease. Lancet. 2017;390(10098):988-1002.

36. Patel $\mathrm{K}$, Janssen DJ, Curtis JR. Advance care planning in COPD. Respirology. 2012:17(1):72-8.

37. Philip J, Gold M, Brand C, Miller B, Douglass J, Sundararajan V. Facilitating change and adaptation: the experiences of current and bereaved carers of patients with severe chronic obstructive pulmonary disease. J Palliat Med. 2014;17(4):421-7.

38. Philip J, Crawford G, Brand C, Gold M, Miller B, Hudson P, Smallwood N, Lau $\mathrm{R}$, Sundararajan V. A conceptual model: redesigning how we provide palliative care for patients with chronic obstructive pulmonary disease. Palliat Support Care. 2017:1-9.

39. Smallwood N, Thompson M, Warrender-Sparkes M, Eastman P, Le B, Irving L, Phillip J. Integrated respiratory and palliative care may improve outcomes in advanced lung disease. ERJ Open Res. 2018:4:00102-2017.

40. Higginson IJ, Bausewein C, Reilly CC, Gao W, Gysels M, Dzingina M, McCrone P, Booth S, Jolley CJ, Moxham J. An integrated palliative and respiratory care service for patients with advanced disease and refractory breathlessness: a randomised controlled trial. Lancet Respir Med. 2014;2(12): 979-87.

41. Ecenarro PS, Iguiniz MI, Tejada SP, Malanda NM, Imizcoz MA, Marlasca LA, Navarrete BA. Management of COPD in end-of-life care by Spanish pulmonologists. COPD. 2018:1-6.

42. Janssen DJ, de Hosson SM, bij de Vaate E, Mooren KJ, Baas AA. Attitudes toward opioids for refractory dyspnea in COPD among Dutch chest physicians. Chron Respir Dis. 2015;12(2):85-92.

43. Smallwood N, Gaffney N, Gorelik A, Irving L, Le B, Philip J. Junior doctors' attitudes to opioids for refractory breathlessness in patients with advanced chronic obstructive pulmonary disease. Intern Med J. 2017;47(9):1050-6.

44. Royal College of Physicians 2015. Census of consultant physicians and specialty traines in the UK: Palliative Medicine 2013-2014. https://www.jrcptb. org.uk. Accessed 10/8/16.

45. Royal College of Physicians 2016. Census of consultant physicians and higher specialty trainees in the UK 2014-2015. https://www.jrcptb.org.uk. Accessed 10/11/17.

46. Cullen, A., The Medical Council of New Zealand: The New Zealand Medical Workforce in 2013 and 2014. https://www.menz.org.nz/assets/News-andPublications/Workforce-Surveys/2013-2014.pdf. Accessed 10/8/16.

Ready to submit your research? Choose BMC and benefit from:

- fast, convenient online submission

- thorough peer review by experienced researchers in your field

- rapid publication on acceptance

- support for research data, including large and complex data types

- gold Open Access which fosters wider collaboration and increased citations

- maximum visibility for your research: over $100 \mathrm{M}$ website views per year

At BMC, research is always in progress.

Learn more biomedcentral.com/submissions 